NBER WORKING PAPER SERIES

\title{
MONETARY AND FISCAL REMEDIES FOR DEFLATION
}

\author{
Alan J. Auerbach \\ Maurice Obstfeld \\ Working Paper 10290 \\ http://www.nber.org/papers/w10290 \\ NATIONAL BUREAU OF ECONOMIC RESEARCH \\ 1050 Massachusetts Avenue \\ Cambridge, MA 02138 \\ February 2004
}

This paper was presented at the 2004 Meetings of the American Economic Association. We thank Ben McCallum, our discussant, for comments. The views expressed herein are those of the authors and not necessarily those of the National Bureau of Economic Research.

(C)2004 by Alan J. Auerbach and Maurice Obstfeld. All rights reserved. Short sections of text, not to exceed two paragraphs, may be quoted without explicit permission provided that full credit, including $(\mathrm{C}$ notice, is given to the source. 
Monetary and Fiscal Remedies for Deflation

Alan J. Auerbach and Maurice Obstfeld

NBER Working Paper No. 10290

February 2004

JEL No.E43, E52, E63

\title{
$\underline{\text { ABSTRACT }}$
}

Prevalent thinking about liquidity traps suggests that the perfect substitutability of money and bonds at a zero short-term nominal interest rate renders open-market operations ineffective for achieving macroeconomic stabilization goals. In an earlier paper, we showed that this reasoning does not hold, that open-market operations can provide substantial macroeconomic benefits and facilitate the use of powerful fiscal policy tools even in a liquidity trap. In this paper, we consider an alternative approach that has been suggested for use in a liquidity trap, a scheduled increase in consumption tax rates. We find that such a policy could, indeed, increase short-run consumption, but would be less effective at increasing welfare or accelerating a country's exit from a liquidity trap. Though a variant of this tax policy might induce exit from a liquidity trap, the impact of welfare is negative in this case as well. We also argue that this alternative tax-rate-based approach is subject to more severe credibility problems than the monetary policy approach explored in our original paper.

\author{
Alan J. Auerbach \\ Department of Economics \\ 549 Evans Hall, \#3880 \\ University of California, Berkeley \\ Berkeley, CA 94720-3880 \\ and NBER \\ auerbach@econ.berkeley.edu \\ Maurice Obstfeld \\ Department of Economics \\ 549 Evans Hall, \#3880 \\ University of California, Berkeley \\ Berkeley, CA 94720-3880 \\ and NBER \\ obstfeld@berkeley.edu
}


Japan's inability to escape the quicksand of deflation and stalled growth has inspired numerous proposals for policy intervention. At the same time, Japan has provided the spectacle of zero short-term nominal interest rates, absent from world economic experience since the 1930s. For central bankers and academic economists alike, the apparent return of the Keynesian liquidity trap inspires a mixture of fear and fascination.

Adverse aggregative performance is, unfortunately, far from being Japan's only current economic problem. In addition, the country's financial institutions are deeply troubled and its public finances seem to be on an unsustainable trajectory. The complex interplay of these problems has served to perpetuate policy inaction by the Japanese authorities. For example, the possible negative effects of higher interest rates on banks and on the government's interest bill are held up as reasons to avoid aggressive fiscal expansion.

In earlier work, we showed that monetary and fiscal expansion can interact in a complementary manner, leading to potentially large welfare gains, even for an economy in which the short-term nominal interest rate currently is zero (see Alan J. Auerbach and Maurice Obstfeld, 2003). Provided they are viewed as permanent by the public, central-bank purchases of government debt with money simultaneously raise prices, stimulate output, and reduce government liabilities outstanding, thereby allowing an immediate tax cut with further stimulating effects. We analyzed qualitative and quantitative implications of this policy within a dynamic general-equilibrium model with sticky prices and distorting taxes.

Some commentators have expressed skepticism of monetary responses to actual or potential deflation, however. One concrete alternative, advanced by Martin Feldstein (2002), calls for enacting an increasing rate of value-added tax, accompanied by a gradual cut in the income tax that renders the entire policy package revenue neutral at each point in time. The 
resulting intertemporal substitution effect, Feldstein argues, would restore positive inflation while stimulating consumption spending in the short run. Over the longer term, the policy would facilitate a transition from an income tax to a consumption tax, with further potential gains in economic efficiency. Thus, the policy would target both short-run stimulus and long-run tax reform, without increasing fiscal deficits or running the risk of money-supply overshooting.

In this paper we apply our dynamic equilibrium model to the Feldstein proposal, focusing in particular on the effects of an announced increase in the rate of consumption taxation. ${ }^{1}$ There are two main conclusions. First, an increasing path of consumption taxes need not accelerate the economy's exit from a liquidity trap. Second, even when that exit is brought forward in time, the policy is harmful to economic welfare.

\section{Sketch of the Model $^{2}$}

A representative household maximizes lifetime utility of consumption $\left(C_{t}\right)$ and labor $\left(L_{t}\right)$,

$$
U_{0}=\sum_{t=0}^{\infty}\left(\prod_{s=0}^{t} \beta_{s}\right) U\left(C_{t}, L_{t}\right)=\beta_{0} U\left(C_{0}, L_{0}\right)+\beta_{0} \beta_{1} U\left(C_{1}, L_{1}\right)+\beta_{0} \beta_{1} \cdots \beta_{t} U\left(C_{t}, L_{t}\right)
$$

We impose the condition that the discount factor $\beta$ is less than 1 in the long run but allow it to vary exogenously in the short run. Period utility takes the form

$U\left(C_{t}, L_{t}\right)=\left(1-\frac{1}{\gamma}\right)^{-1} C_{t}^{1-\frac{1}{\gamma}}-k_{t} L_{t}$

where $\gamma$ is the intertemporal elasticity of consumption substitution. The parameter $k_{t}$ formally measures the disutility of labor, but $1 / k_{t}$ is isomorphic in the model to the level of labor productivity. There is perfect foresight and the household faces a standard intertemporal budget

${ }^{1}$ The simplicity of our model does not allow us to distinguish the further, long-run welfare effects of a change in the tax base from income to consumption; nor will we touch upon some accompanying proposals by Feldstein that center on fiscal investment incentives. 
constraint for that case, with $i_{t}$ denoting the nominal interest rate between dates $t-1$ and $t$. Money demand is determined by the cash-in-advance constraint $M_{t} \geq\left(1+\tau_{t}\right) P_{t} C_{t}$,

where $\tau_{t}$ is the proportional consumption tax (a key distortion in the model), $P_{t}$ is the price level, and $M_{t}$ is the (beginning-of-period) money supply. This constraint may not bind, of course, when $i_{t}=0$. The government (consolidated fiscal and monetary authorities) issues one-period nominal debt and finances its outlays through seigniorage and consumption-tax proceeds. Government purchases are set at an exogenous level and their impact on welfare is assumed separable.

On the economy's production side there are two sectors, each containing a continuum of monopolistic producers of differentiated goods. The overall consumption index $C$ above is an equal-weights Cobb-Douglas function of consumption of the two sectors' respective products, with the sectoral consumption subindexes CES with intratemporal substitution elasticity $\rho$. Under sticky prices, the sectors alternate in setting nominal product prices that are maintained for two periods. This staggering disappears when prices are flexible. Output is linear in labor input (there is no capital in the model), so in the flexible-price case, price is a constant markup over the nominal wage $w, P=\rho w /(\rho-1)$.

The solution for equilibrium consumption is

$$
C_{t}=\left(\frac{w_{t}}{k_{t}\left(1+i_{t}\right)\left(1+\tau_{t}\right) P_{t}}\right)^{\gamma}
$$

There are three causes of departure from Pareto optimality in the model, and expression (3) illustrates that consumption depends negatively on all three of them: the monopolistic markup

${ }^{2}$ For a more detailed description of the model, see Auerbach and Obstfeld (2003). 
$P / w$, the departure from the "optimum quantity of money" interest rate of $i=0$, and the positive tax on consumption, $\tau$.

A key requirement for effective monetary policy is the expectation that, at some point in the future, the short-term nominal interest rate will turn positive. Suppose that the nominal interest rate is currently zero, and let $t=T-1$ be the date upon which it first happens that $i_{t+1}>0$. (Our simulations, described below, endogenize that date.) Using (2), (3), and the consumer's intertemporal Euler equation, one can derive conditions linking the evolution of nominal wages and prices:

$$
\begin{array}{ll}
\frac{w_{t}}{k_{t}}=\left(\prod_{s=t+1}^{T-1} \beta_{s}^{-1}\right) \frac{1}{\beta_{T}} M_{T}^{\frac{1}{\gamma}}\left(P_{T}\left(1+\tau_{T}\right)\right)^{1-\frac{1}{\gamma}}, & t \leq T-1, \\
\frac{w_{t}}{k_{t}}=\frac{1}{\beta_{t+1}} M_{t+1}^{\frac{1}{\gamma}}\left(P_{t+1}\left(1+\tau_{t+1}\right)\right)^{1-\frac{1}{\gamma}}, & t \geq T-1 .
\end{array}
$$

The implications of these equations are most easily seen when $\gamma=1$ (logarithmic consumption preferences) or when prices are flexible (so that $P_{t}$ is proportional to $w_{t}$ ). In those cases (and indeed, in general, even with staggered prices and $\gamma \neq 1$, although the analysis is more complicated), only expectations of the money supply on date $T$ matter for nominal wage and price determination. This is the hallmark of the liquidity trap. In a liquidity trap, nominal prices fall at the real rate of interest toward the terminal equilibrium price prevailing on the first date at which the demand for money is determined in the "normal" fashion by liquidity preference.

Our previous analysis showed that being in a liquidity trap does not preclude the effective use of monetary policy, if that monetary policy takes the form of a change in the stock of money that is sustained through date $T$. Monetary policy may also be used to spur a more rapid departure from the liquidity trap, but this transition is not necessary for monetary policy to affect 
current output and prices. Announced, credible changes in the future money stock can stimulate current aggregate demand while at the same time facilitating reductions in distortionary taxation. That analysis assumed, for simplicity, that the rate of consumption tax was held constant over time for each particular equilibrium path, equal to the rate necessary to satisfy the government's intertemporal budget constraint. In the spirit of Feldstein's proposal, we now consider the impact of a shift from a constant tax rate path to one with rates that are initially low, in the initial liquidity-trap regime, and rise over time to a constant, long-run level consistent with intertemporal budget balance.

\section{Simulation Approach}

We solve the model backward, following the technique laid out in more detail in Auerbach and Obstfeld (2003). Assume first that we know the state of the economy at date $t+1$, including whether the economy is in a liquidity trap. (This will turn out not to be a restrictive assumption, if it is consistent with the resulting equilibrium path.) We may then solve for the values of the wage rate, $w$, the price level, $P$, and the interest rate, $i$, at date $t$, and then proceed to date $t-1$, and so on. This recursive procedure provides a solution for the entire path of the economy for given paths of the policy variables $M$ and $\tau$. In order to ensure that the government's intertemporal budget constraint is satisfied, we then iterate, revising the values of $\tau$ with each iteration to meet the budget constraint. Once the iteration process converges, the values of $\tau$ to which behavior responds are consistent with the government's budget constraint, given that behavior.

Except for assumptions about the path of $\tau$ and the value of the intertemporal consumption elasticity, $\gamma$, we adopt the parameter values used in our earlier paper. In particular, in order to generate an initial equilibrium path that starts out in a liquidity trap, we assume that the discount factor, $\beta$, is initially greater than 1 -the pure rate of discount is negative, and this 
patience on the part of consumers pushes down the equilibrium interest rate. The value of $\beta$ is assumed to fall after 5 years, possibility reflecting changes in demography, risk preferences, or other household attributes not explicitly modeled. We also assume that the productivity parameter, $k$, falls over time, this effective rise in productivity leading to growth in real money balances, as has occurred recently in Japan. ${ }^{3}$

\section{Monetary and Fiscal Policy Simulations}

Table 1 presents results for four simulations that assume logarithmic utility and sticky prices. Each panel presents the trajectories of four key variables for a particular simulation-the nominal interest rate $(i)$, the inflation rate $(\pi)$, aggregate consumption $(C)$, and the tax rate $(\tau$, expressed on a tax-inclusive basis, i.e., as a share of gross-of-tax rather than net-of-tax expenditures). The results are presented for six periods, beginning with the period of the policy change and ending with the period during which the economy exits from the liquidity trap in the base case simulation. Also shown for each simulation (other than the base case) is the welfare gain, measured as the policy's equivalent variation increase in the present value of lifetime resources relative to the base case.

In the base case, the nominal interest rate is zero through period 5 , after which it rises to 4 percent. The inflation rate is negative while the economy is in the liquidity trap, consumption grows, and the tax rate, by assumption, is constant. The panel in the table's upper left shows the

\footnotetext{
${ }^{3}$ The parameterization of our base case simulation is as follows. We set the discount factor $\beta$ initially at $1 / 0.97$, falling to $1 / 1.02$ in period 5 . We adjust the share of government purchases so that the constant tax rate in the initial equilibrium equals a recent estimate for government's share of output in Japan, 47 percent. We set the initial ratio of high-powered money to highpowered money plus government debt at 0.2 . We assume that the labor-disutility parameter, $k$, falls at an annual rate of 0.05 , reaching 1.0 in period 5 , when it ceases falling and remains constant thereafter. We set the intratemporal demand elasticity, $\rho$-effectively a competition parameter - equal to 10, which induces a modest price-cost ratio of 10/9. Finally, in the initial equilibrium, we assume that the money stock grows at a constant annual rate of 2 percent.
} 
impact of an immediate and permanent 10-percent increase in the money stock. This policy increases inflation for two periods, spurs consumption in the short-run, due to the sluggish price response, and also increases consumption in the long run, as a result of the lower tax rate made feasible by lower real government debt. These increases in short-run and long-run consumption are associated with a 0.8 percent increase in welfare. Note that this policy increases welfare without disrupting the liquidity trap itself, illustrating that it is the ability to conduct policy in a liquidity trap that is key, not the ability to eliminate the liquidity trap itself. An alternative monetary policy simulation, shown in the lower left, does deliver the economy immediately from the liquidity trap via an immediate increase in money growth. This policy, like the previous one, raises consumption in the short run, but its long-run effects and overall welfare gain are reduced by the very fact that interest rates are positive, thereby increasing one of the three consumption distortions.

The final panel in Table 1 gives results for a simulation in which the tax rate is set initially at a low level and then allowed to grow smoothly to its equilibrium level in period 5 . As predicted, this spurs short-run consumption, much more than in any other simulation. But this increase in consumption is only temporary. In the long run, the consumption tax rate must rise to pay for the temporary tax cut, leading consumption to fall below its level in the base case. This long-run drop in consumption more than outweighs the short-run increase. The intuition for this result comes from the tax-smoothing literature, which indicates that, all else equal, consumption tax rates should be equal over time to minimize intertemporal distortions. Varying consumption tax rates is therefore welfare reducing. Indeed, because the short-run drop in consumption taxes (unlike the previously considered money stock increase) stimulates demand without compressing price-cost margins, this potential source of welfare gain is absent. 
Interestingly, this policy of tax-based demand stimulus has no impact on nominal interest rates or the duration of the liquidity trap. This is because the policy increases the demand for goods, but not for money. Indeed, with logarithmic utility and $\gamma=1$ (see expression 3 ), expenditure on goods, $(1+\tau) P C$, does not vary with the full price of goods, $(1+\tau) P$. Hence, the demand for money, which equals expenditure, does not vary either, and there is no reduction in the excess supply of money. As Table 2 shows, this invariance result breaks down when the intertemporal consumption elasticity, $\gamma$, is not equal to $1 .^{4}$ The table provides simulations of tax rate growth policies that successfully bring the economy out of a liquidity trap, for two alternative values of $\gamma, 1.333$ and 0.8 . But note that, for $\gamma<1$ (empirically, the more likely case), this calls for tax rates to fall over time. Given that consumption demand is inelastic, the demand for money actually declines with a reduction in the tax rate, so a short-run increase in money demand requires a tax rate that is initially higher. Note, too, that, in both policy experiments, the tax-rate variation - whether rising or falling - reduces welfare. As discussed above in the context of monetary policy, escaping the liquidity trap, in itself, should not be a fundamental policy objective, if salutary policies remain available in the presence of very low interest rates. Tax rate variation may succeed in eliminating the liquidity trap, but the underlying policy justification remains weak.

\section{A Further Issue: Credibility}

We have demonstrated that monetary policy can remain effective in a liquidity trap, and that tax rate variation, while also effective at stimulating short-run demand, lacks the welfare-enhancing properties of an immediate, credibly permanent monetary expansion. But credibility is a key requirement for monetary policy effectiveness, so one might ask whether alternative polices,

\footnotetext{
${ }^{4}$ For simplicity, the simulations in this table assume flexible pricing.
} 
such as the tax rate variations considered above, are more attractive in this regard. In particular, will it be easier for a government to maintain a commitment to raise tax rates over time than to maintain an increase in the money supply? We would argue, to the contrary, that the tax policy will be more difficult to maintain. The government would forgo seigniorage it has already captured by reversing an open market operation purchase of bonds; it has every incentive not to do so, even if the economy's response to its policy is delayed. On the other hand, a government that has promised to raise consumption taxes, if confronted by an initial lack of economic response, may find it difficult to adhere to such a promise in the face of continued weakness in consumption demand. Thus, the monetary policy approach remains preferred. 


\section{References}

Auerbach, Alan J. and Maurice Obstfeld. "The Case for Open-Market Purchases in a Liquidity Trap.” National Bureau of Economic Research (Cambridge, MA) Working Paper No. 9814, July 2003.

Feldstein, Martin. “Commentary: Is There a Role for Discretionary Fiscal Policy?” in Rethinking

Stabilization Policy. Kansas City, MO: Federal Reserve Bank of Kansas City, 2002, pp. 151-62. 


\section{Table 1}

The Impact of Monetary and Fiscal Policy

(logarithmic utility and staggered price-setting)

Simulation:

$\underline{\text { Period }}$

$\begin{array}{rrrrr}\underline{i} & \underline{\underline{i}} & \underline{\underline{\tau}} & \underline{\tau} \\ 0 & .00 & -.02 & .37 & .47 \\ 1 & .00 & -.02 & .39 & .47 \\ 2 & .00 & -.02 & .41 & .47 \\ 3 & .00 & -.02 & .43 & .47 \\ 4 & .00 & -.01 & .45 & .47 \\ 5 & .04 & .01 & .46 & .47\end{array}$

Welfare Gain

Simulation:

Period

0

1

2

3

4

Welfare Gain

\section{Double Money Growth Rate}

$\begin{array}{rrr}\underline{i} & \underline{\pi} & \underline{\underline{C}} \\ .01 & .01 & .38 \\ .01 & .02 & .39 \\ .01 & -.01 & .41 \\ .01 & -.01 & .43 \\ .01 & .00 & .45 \\ .04 & .01 & .46\end{array}$

.005
Increase Money Stock by $\mathbf{1 0 \%}$

$\begin{array}{cccc}\underline{i} & \underline{\pi} & \underline{\underline{C}} & \underline{\tau} \\ .00 & .03 & .39 & .46 \\ .00 & .03 & .39 & .46 \\ .00 & -.02 & .42 & .46 \\ .00 & -.02 & .44 & .46 \\ .00 & -.01 & .46 & .46 \\ .04 & .01 & .47 & .46 \\ & .008 & & \end{array}$

Tax Rate Grows

$\begin{array}{cccc}\underline{i} & \underline{\pi} & \underline{\underline{C}} & \underline{\tau} \\ .00 & -.02 & .56 & .20 \\ .00 & -.02 & .55 & .25 \\ .00 & -.02 & .54 & .30 \\ .00 & -.02 & .52 & .36 \\ .00 & -.01 & .49 & .42 \\ .04 & .01 & .45 & .49 \\ & -.005 & & \end{array}$

Table 2

Using Consumption Taxes to Escape the Liquidity Trap (flexible price-setting)

$\gamma=1.333:$

$\underline{\text { Period }}$

$\begin{array}{rrrrr}0 & \underline{\underline{i}} & \underline{\underline{\pi}} & \underline{\underline{C}} & \underline{\tau} \\ 1 & .00 & -.02 & .26 & .47 \\ 2 & .00 & -.02 & .28 & .47 \\ 3 & .00 & -.02 & .30 & .47 \\ 4 & .00 & -.02 & .33 & .47 \\ 5 & .00 & -.02 & .35 & .47 \\ & & .02 & .35 & .47\end{array}$

Welfare Gain

$\gamma=\mathbf{0 . 8}$ :

Period

0

1

2

3

4

Welfare Gain

\section{Base Case}

$\begin{array}{rrrr}\underline{i} & \underline{\pi} & \underline{C} & \underline{\tau} \\ .00 & -.02 & .45 & .47 \\ .00 & -.02 & .47 & .47 \\ .00 & -.02 & .49 & .47 \\ .00 & -.02 & .51 & .47 \\ .00 & -.02 & .53 & .47 \\ .04 & .02 & .54 & .47\end{array}$

\section{Time-Varying Tax Rate}

$\begin{array}{rrrr}\underline{i} & \underline{\pi} & \underline{C} & \underline{\tau} \\ .00 & -.06 & .49 & .16 \\ .00 & -.02 & .49 & .20 \\ .01 & -.01 & .46 & .26 \\ .02 & .00 & .43 & .34 \\ .03 & .01 & .38 & .41 \\ .04 & .02 & .33 & .50 \\ & -.022 & & \end{array}$

Time-Varying Tax Rate

$\begin{array}{cccc}\underline{i} & \underline{\pi} & \underline{\underline{C}} & \underline{\tau} \\ .02 & -.08 & .31 & .66 \\ .02 & .00 & .35 & .62 \\ .02 & .00 & .40 & .59 \\ .02 & .00 & .44 & .55 \\ .01 & -.01 & .50 & .51 \\ .04 & .02 & .54 & .46 \\ & -.007 & & \end{array}$

